\title{
Secagem de fatias de abóboras (Cucurbita moschata, L.) por convecção natural e forçada
}

\author{
Drying of pumpkin (Cucurbita moschata, L.) slices by natural and forced convection \\ Soraia Vilela BORGES ${ }^{1 *}$, Maurício Cordeiro MANCINI ${ }^{2}$, Jefferson Luiz Gomes CORRÊA ${ }^{1}$, \\ Daniela Araujo NASCIMENTO
}

\begin{abstract}
Resumo
A abóbora (Cucurbita moschata, L.) é uma importante fonte de provitamina A, de baixo custo, e sob a forma desidratada oferece diferentes opções de utilização e consumo. Secagens por convecção natural e forçada foram comparadas quanto ao grau de secagem atingido e encolhimento, em função da temperatura, velocidade de ar e dimensões do produto. Os resultados obtidos mostraram que o uso de fatias com volume de $6,25 \mathrm{~cm}^{3}$ em secador por convecção forçada a $50{ }^{\circ} \mathrm{C}$ e à velocidade de $5,5 \times 10^{-4} \mathrm{~ms}^{-1}$ resultaram em produtos de menor encolhimento, sendo recomendadas estas condições.
\end{abstract}

Palavras-chave: desidratação; vegetais; cinética.

\begin{abstract}
Besides its low price, Pumpkin (Cucurbita moschata, L.) is an important source of provitamin-A, and when dehydrated it offers different options of utilizations and consumption. Natural and forced convection drying were compared according to the drying degree shrinkage as a function of temperature, and air velocity and product dimensions. The obtained results showed that slices with the volume of $6.25 \mathrm{~cm}^{3}$ in forced convection oven at $50{ }^{\circ} \mathrm{C}$ and at the velocity of $5.5 \times 10^{-4} \mathrm{~ms}^{-1}$ resulted in a lower shrinkage products, so these conditions were recommended.
\end{abstract}

Keywords: dehydration; vegetable; kinetics.

\section{Introdução}

A abóbora (Cucurbita moschata, L.) constitui uma excelente fonte de carotenóides, precursor da vitamina A (ARIMA; RODRÍGUEZ-AMAYA, 1990; MURKOVIC; MULLEDER; NEUNTEU, 2002), de baixo custo. Sob a forma desidratada, pode ser conservada por mais tempo e utilizada em várias preparações culinárias, contribuindo com mais uma opção alimentícia para combater a hipoavitaminose A, que afeta milhares de crianças no Brasil e no mundo.

O processo de secagem é uma das técnicas mais antigas documentadas na literatura para reduzir a atividade de água do alimento, responsável pela sua alta perecibilidade. Dentre elas, podemos citar os processos de secagem por convecção natural (feita geralmente em estufas), circulação forçada (em diferentes tipos de secadores), aplicados a uma grande variedade de frutas e vegetais (KARATHANOS, 1999; NICOLETI; TELIS-ROMERO; TELIS, 2001; PARK; YADO; BROD, 2001; ARÉVALO-PINEDO; MURR, 2005; LEITE; MANCINI; BORGES, 2007).

Os parâmetros de controle podem variar de acordo com o processo, mas em geral a temperatura, tempo de secagem e a dimensão do alimento são influentes em qualquer processo de secagem, pois exercem efeitos sobre a taxa de secagem, teor de umidade final e encolhimento do produto, características estas relacionadas com a preservação e qualidade do alimento, (KARATANOS, 1999; QUEIROZ; NEBRA, 2001; NICOLETI; TELIS-ROMERO; TELIS, 2001, LEWICKI; PAWLAK, 2003). Na secagem por circulação forçada, uma variável importante a controlar é a velocidade do ar de secagem, relacionada com a taxa de secagem (QUEIROZ; NEBRA, 2001; PARK; YADO; BROD, 2001; KROKIDA et al., 2003). Verificou-se, naqueles trabalhos, que altas taxas de secagem são alcançadas quando se eleva a temperatura ou velocidade do ar, e o tamanho do alimento diminui, porque há um aumento no coeficiente de difusão da umidade, e o grau de umidade desejado é alcançado mais rapidamente. Entretanto, durante o processo de secagem, pode-se observar a diminuição das dimensões do produto, devido à alteração na microestrutura do tecido fresco, em que se verifica um aumento de cavidades, células alongadas, dentre outras modificações descritas por Lewicki e Pawlak (2003), promovidas pelo stress térmico e principalmente pela remoção de umidade. Este fenômeno, conhecido como encolhimento, tem sido discutido em várias pesquisas e nota-se um comportamento diferente para cada alimento estudado e para cada geometria (MANDABA; DRISCOL; BUCLE, 1994; MOREIRA; FIGUEIREDO; SERENO, 2000; MULET et al., 2000; PUIGALLI; JOMAA; JANNOT, 2004; KINGSLY et al., 2007). De acordo com os resultados de Moreira

Recebido para publicação em 15/6/2007

Aceito para publicação em 22/1/2008 (002605)

Departamento de Ciência dos Alimentos, Universidade Federal de Lavras - UFLA, Campus Universitário, CEP 37200-000, Lavras - MG, Brasil,

E-mail:sborges@ufla.br; jefferson@ufla.br

${ }^{2}$ Departamento de Engenharia Química, Universidade Federal Rural do Rio de Janeiro - UFRRJ, Km 47 da Antiga Rodovia Rio - SP, CEP 23851-970, Seropédica - RJ, Brasil, E-mail:mancini@ufrrj.br; westdani@ig.com.br

${ }^{*}$ A quem a correspondência deve ser enviada 
et al. (2000), em um estudo de secagem de maçãs por ar quente e também por liofilização para diferentes teores de umidade, o grau de encolhimento dependeu da relação diâmetro/espessura de maçãs desidratadas. Em maiores teores de umidade, o diâmetro diminui mais que a espessura e em menores teores; o inverso ocorre. $\mathrm{O}$ encolhimento está ligado à remoção de água e quanto mais água é retirada, maior é o encolhimento, resultados também encontrados por Kingsly et al. (2007) para Ber, uma fruta indiana. Correlações lineares entre encolhimento e teor de umidade foram determinadas por McMinn e Magee (1997) para amostras cilíndricas de batata. Correlações similares foram descritas para outros alimentos (PARK, 1998; HERNANDES; PAVON; GARCIA, 2000). Outros tipos de correlação são mostrados por Mayor e Sereno (2004) em uma ampla revisão sobre encolhimento de diferentes alimentos.

Alguns trabalhos recentes no Brasil têm sido encontrados a respeito de secagem de abóbora. Coelho et al. (2002) desenvolveram um trabalho de secagem de abóbora precedido de desidratação osmótica. Estes autores observaram um maior grau de secagem em convecção forçada com relação à convecção natural. Isto atesta a influência da velocidade do ar em secagem de tal material. Arévalo-Pinedo e Murr (2005) verificaram a influência da pressão, temperatura e pré-tratamentos (branqueamento e congelamento), sobre a taxa de secagem a vácuo. Os resultados mostraram que maiores taxas de secagem foram alcançadas à temperatura de $70{ }^{\circ} \mathrm{C}$ e $5 \mathrm{kPa}$ para amostras congeladas, porque o congelamento aumentou a porosidade, favorecendo a secagem. Com o objetivo de reduzir a hipoavitaminose A, Ambrósio, Campos e Faro (2006) avaliaram sensorialmente flocos de abóbora desidratados em tambor rotativo, adicionados em feijão e pirão, e obtiveram alta aceitabilidade por parte de adultos $(95,21 \%)$ e crianças $(95,52 \%)$.

Baseado no exposto, este trabalho tem o objetivo de avaliar o teor de umidade final e o encolhimento para a secagem por convecção natural e convecção forçada, a fim de selecionar o melhor método para produção de fatias de abóbora desidratadas.

\section{Material e métodos}

\subsection{Matéria-prima}

A matéria-prima utilizada neste trabalho foi a abóbora (Curcubita moschata L.), selecionada visualmente de acordo com a coloração externa (verde escura) e polpa (alaranjada e firme).

\subsection{Pré-preparo da abóbora}

Selecionada e previamente pesada, a abóbora, foi submetida à pré-lavagem em água corrente à temperatura ambiente e sanificada com solução $150 \mathrm{ppm}$ de cloro residual livre por 15 minutos. Em seguida, a matéria-prima sofreu primeiramente quarteamento com faca de aço inoxidável, remoção das sementes e raspagem na parte central para retirada de toda a película que envolve as sementes. Para a redução de tamanho, a abóbora foi fracionada na espessura de $0,50 \mathrm{~cm}$, em fatiador elétrico para vegetais e posicionada sob gabaritos previamente confeccionados de material plástico de diferentes dimensões, sendo contornada à faca, para desta forma se obter tamanhos uniformes. Obtiveram-se fatias de mesma espessura com três tamanhos diferentes, resultando em três moldes com as dimensões, a saber: $A_{1}$ com área de $7,5 \times 10^{-4} \mathrm{~m}^{2}$, largura de $1,50 \times 10^{-2} \mathrm{~m}$ e comprimento de $5,00 \times 10^{-2} \mathrm{~m} ; \mathrm{A}_{2}$ com área de $12,5 \times 10^{-4} \mathrm{~m}^{2}$, largura de $2,50 \times 10^{-2} \mathrm{~m}$ e comprimento de $5,00 \times 10^{-2} \mathrm{~m}$; e $\mathrm{A}_{3}$ com área de $10,5 \times 10^{-4} \mathrm{~m}^{2}$, largura de $1,50 \times 10^{-2} \mathrm{~m}$ e comprimento de $7,00 \times 10^{-2} \mathrm{~m}$.

As fatias de abóbora foram acondicionadas em sacos plásticos herméticos e mantidas em refrigeração até o momento de serem desidratadas.

\subsection{Secagem}

Todos os experimentos foram feitos em triplicata e os resultados foram expressos como a média de 3 determinações.

\section{Convecção natural}

Utilizou-se uma estufa com as dimensões $100 \mathrm{~cm}$ de altura, $52 \mathrm{~cm}$ largura e $97 \mathrm{~cm}$ de comprimento. As variáveis de controle foram temperatura $\left(50,60\right.$ e $\left.70^{\circ} \mathrm{C}\right)$ e dimensões das fatias de abóbora. As fatias foram dispostas em bandejas forradas com papel laminado, pesadas e dispostas na unidade de secagem. Em intervalos pré-determinados (0, 60, 120, 240, 360 e 420 minutos) foram pesadas para avaliação do grau de secagem e somente no final do experimento foi medido o encolhimento.

\section{Secagem por convecção forçada}

Foi utilizado um minissecador de circulação forçada, cujas dimensões e controle operacional foram descritos por Leite (2002). As variáveis de controle foram velocidade do ar de secagem em 2 níveis: $5,5 \times 10^{-4} \mathrm{~ms}^{-1}$ e $1,65 \times 10^{-3} \mathrm{~ms}^{-1}$, temperatura do ar de secagem de 50,60 e $70{ }^{\circ} \mathrm{C}$ e dimensões das fatias de abóbora. A umidade relativa do ar ambiente, a $25^{\circ} \mathrm{C}$ esteve na faixa de $60 \%$, sendo a umidade relativa do ar no secador de 15,4, 9,55 e 6,11\% nas temperaturas de 50, 60 e $70{ }^{\circ} \mathrm{C}$, respectivamente.

\subsection{Determinação do teor de umidade}

O teor de umidade foi determinado segundo a AOAC (2002), em triplicata e expresso em base seca (g.100 g ${ }^{-1}$ sólidos secos).

\subsection{Determinação do encolhimento}

A altura, largura e espessura das fatias foram medidas com paquímetro. Foram feitas 5 medidas em diferentes pontos das dimensões, tomando o valor médio destas medidas.

\subsection{Modelo cinético}

As curvas de cinética de secagem foram ajustadas utilizando-se um modelo exponencial, o qual relaciona a relação teor de umidade/teor de umidade inicial e o tempo de secagem, conforme adotado previamente por Alcina, Silva e Brasileiro (1997) e Cano-Chauca et al. (2004). 
Considerou-se que (Equação 1):

$\frac{\mathrm{dYs}^{*}}{\mathrm{dt}}=-\mathrm{kYs} \mathrm{s}^{*}$

onde (Equação 2):

$\mathrm{Ys}^{*}=\frac{\mathrm{Ys}}{\mathrm{Ys}_{0}}$

com a condição inicial

$$
\mathrm{Ys}^{\star}(0)=1
$$

Desta forma, a evolução de $\mathrm{Y}_{\mathrm{s}}$ com o tempo é dada por (Equação 3):

$\mathrm{Ys}^{*}=\mathrm{k}_{0} \exp \left(-\mathrm{k}_{1} \mathrm{t}\right)$

onde $\mathrm{k}_{0}$ corresponde à condição inicial e deve ser próximo da unidade.

Os dados ajustados pela Equação 3 foram avaliados quanto ao coeficiente de correlação $\left(\mathrm{r}^{2}\right)$ e erro padrão (SE), de acordo com Pimentel-Gomes (1999).

\section{Resultados e discussão}

\subsection{Convecção natural}

A Figura 1 apresenta a cinética de secagem da abóbora por convecção natural a $50{ }^{\circ} \mathrm{C}$ com amostras com diferentes áreas de exposição. Verifica-se que a geometria $\mathrm{A}_{3}$ apresentou uma tendência a conduzir a um maior grau de secagem. Igual comportamento foi encontrado ao se trabalhar com temperaturas de 60 e $70^{\circ} \mathrm{C}$ (Figuras 2 e 3 ). Comparando as referidas figuras e a Figura 4 , para $\mathrm{A}_{3}$, verifica-se que, com o aumento da tempe-

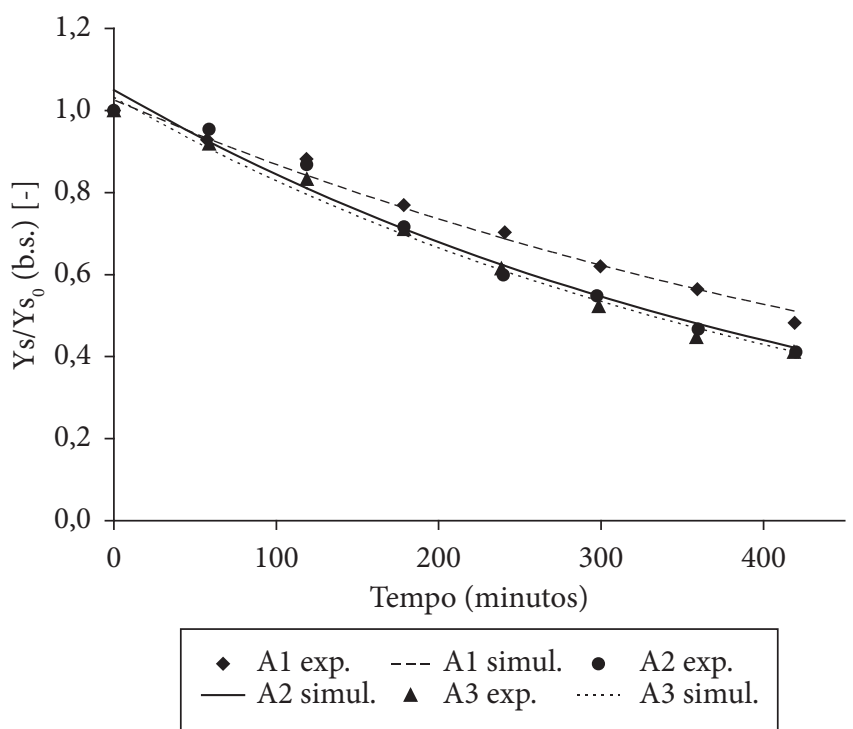

Figura 1. Cinética de secagem de abóbora, com diferentes áreas, desidratada por convecção natural à temperatura de $50^{\circ} \mathrm{C}$, onde $\mathrm{A}_{1}, \mathrm{~A}_{2}$ e $\mathrm{A}_{3}$ correspondem a áreas de $7,5 \times 10^{-4} \mathrm{~m}^{2}, 12,5 \times 10^{-4} \mathrm{~m}^{2} \mathrm{e} 10,5 \times 10^{-4} \mathrm{~m}^{2}$, respectivamente; e as abreviações exp. e simul. correspondem a experimental e simulação, respectivamente. ratura, obtém-se um maior grau de secagem, traduzido em um menor teor de umidade. Segundo diversos autores, o aumento da temperatura conduz ao aumento do coeficiente de difusão da água, acelerando o processo de secagem (QUEIROZ; NEBRA, 2001; NICOLETI; TELIS-ROMERO; TELIS, 2001; PARK; YADO; BROD, 2001; ARÉVALO-PINEDO; MURR, 2005).

A Tabela 1 mostra os efeitos da temperatura sobre o grau de encolhimento das fatias de abóboras de diferentes áreas. Observa-

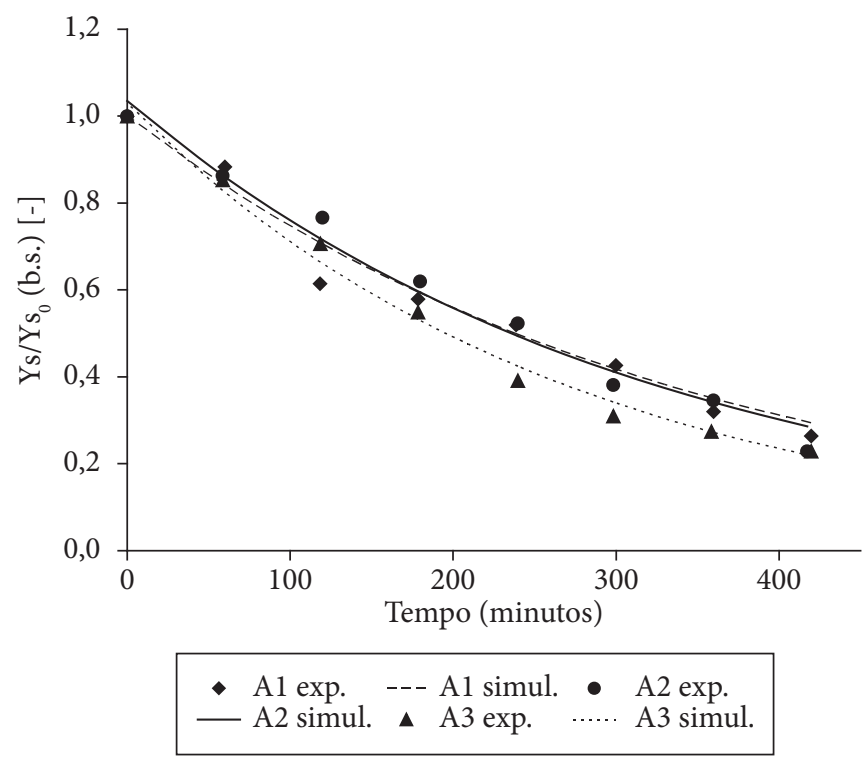

Figura 2. Cinética de secagem de abóbora, com diferentes áreas, desidratada por convecção natural à temperatura de $60^{\circ} \mathrm{C}$, onde $\mathrm{A}_{1}, \mathrm{~A}_{2}$ e $\mathrm{A}_{3}$ correspondem a áreas de $7,5 \times 10^{-4} \mathrm{~m}^{2}, 12,5 \times 10^{-4} \mathrm{~m}^{2}$ e $10,5 \times 10^{-4} \mathrm{~m}^{2}$, respectivamente; e as abreviações exp. e simul. correspondem a experimental e simulação, respectivamente.

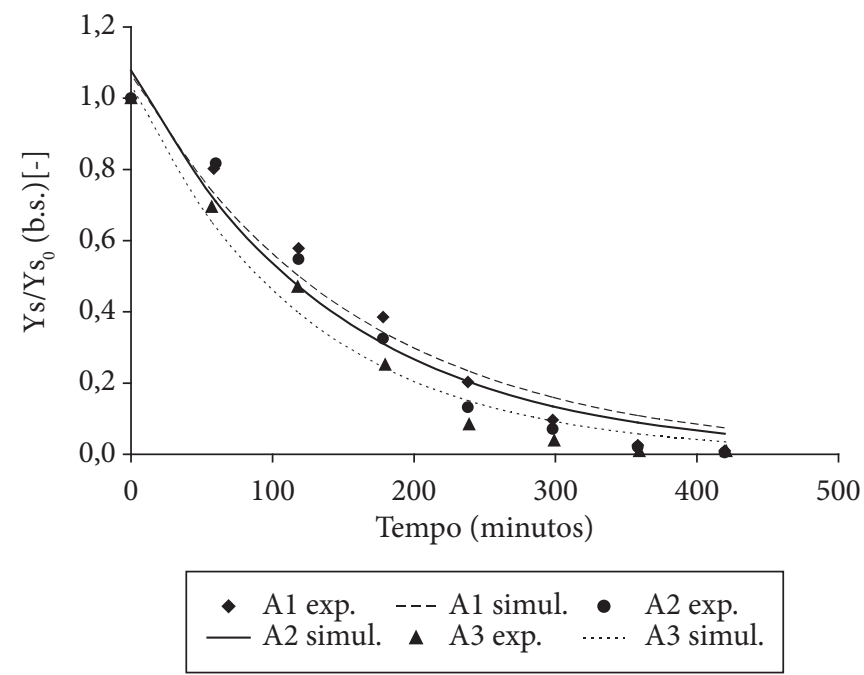

Figura 3. Cinética de secagem de abóbora, com diferentes áreas, desidratada por convecção natural à temperatura de $70^{\circ} \mathrm{C}$, onde $\mathrm{A}_{1}, \mathrm{~A}_{2}$ e $\mathrm{A}_{3}$ correspondem a áreas de $7,5 \times 10^{-4} \mathrm{~m}^{2}, 12,5 \times 10^{-4} \mathrm{~m}^{2} \mathrm{e} 10,5 \times 10^{-4} \mathrm{~m}^{2}$, respectivamente; e as abreviações exp. e simul. correspondem a experimental e simulação, respectivamente. 
se que as dimensões das amostras foram afetadas pelo aumento da temperatura, sendo os efeitos mais pronunciados na espessura e largura para todas as geometrias. Percebe-se que a amostra $\mathrm{A}_{1}$ sofreu uma menor redução na espessura em relação à $A_{2}$ e $A_{3}$. Para o formato $\mathrm{A}_{3}$, houve encolhimento mais pronunciado na largura e menor para o comprimento em relação às outras áreas. Além disso, verificou-se que este formato atingiu o maior grau de secagem em qualquer temperatura (Figuras 1 a 3). Verificou-se comportamento semelhante no trabalho de Mulet et al. (2000) que analisaram o encolhimento em batatas desidratadas de diferentes geometrias, no qual maiores taxas, resultantes do aumento de temperatura de secagem, resultaram em maior encolhimento e dimensões menores tendem a encolher mais. Com base nas Figuras de 1 a 3 e na Tabela 1, pode-se concluir que a geometria $\mathrm{A}_{2}$ é a mais conveniente para a secagem de abóbora por convecção natural, uma vez que, à mesma temperatura, o teor final de umidade é bastante semelhante ao obtido para a geometria $\mathrm{A}_{3}$, porém apresentando o menor encolhimento volumétrico dentre todas as geometrias aqui estudadas.

\subsection{Convecção forçada}

As Figuras 5 e 6 apresentam cinéticas de secagem de abóbora em experimentos de convecção forçada com a variação da área, da temperatura, respectivamente. Pela análise das Figuras 5 e 6, comparadas com as Figuras de 1 a 4, verifica-se que, semelhantemente, à secagem por convecção natural, a secagem por convecção forçada apresenta as mesmas tendências com relação à variação de área e variação de temperatura.

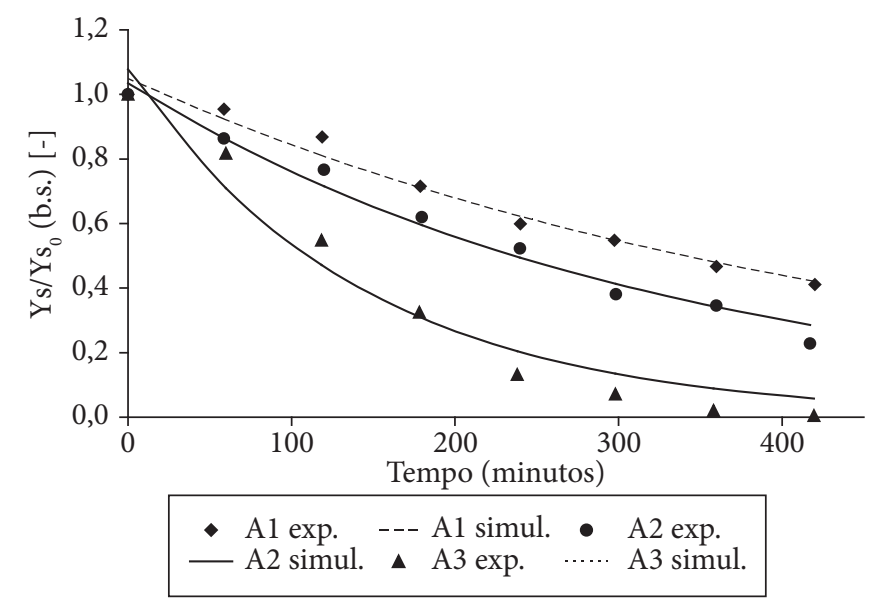

Figura 4. Cinética de secagem de abóbora, com área de 10,5 × $10^{-4} \mathrm{~m}^{2}$, desidratada por convecção natural a diversas temperaturas; e as abreviações exp. e simul. correspondem a experimental e simulação, respectivamente.
A Figura 7 compara resultados de cinética de secagem em regime de convecção natural e de convecção forçada e nota-se uma redução significativa do teor de umidade ao se alterar o modo

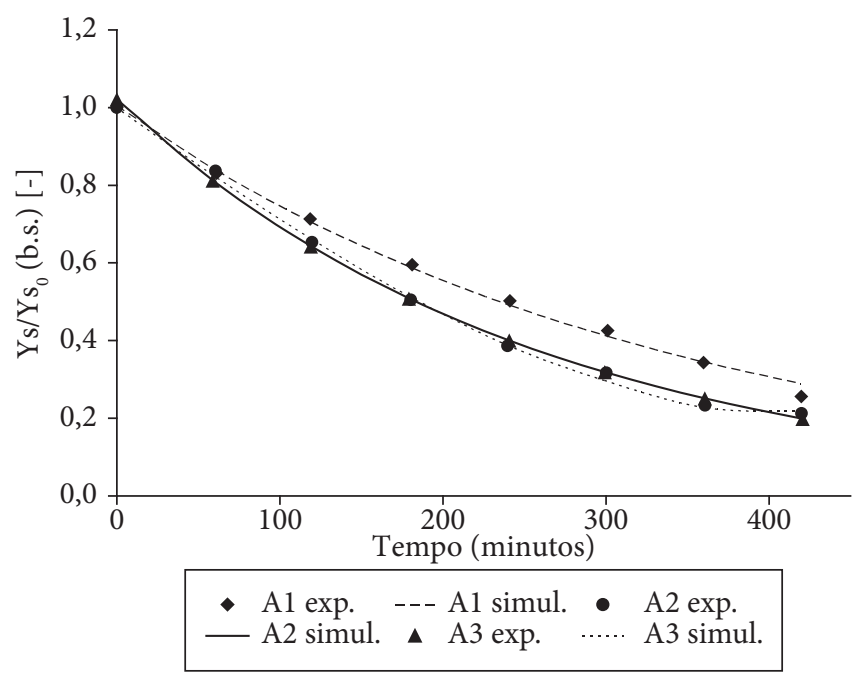

Figura 5. Cinética de secagem de abóbora, com diferentes áreas, desidratada por convecção forçada com ar a $50{ }^{\circ} \mathrm{C}$ e velocidade de $5,5 \times 10^{-4} \mathrm{~ms}^{-1}$, onde $A_{1}, A_{2}$ e $A_{3}$ correspondem a áreas de $7,5 \times 10^{-4} \mathrm{~m}^{2}$, $12,5 \times 10^{-4} \mathrm{~m}^{2}$ e $10,5 \times 10^{-4} \mathrm{~m}^{2}$, respectivamente; e as abreviações exp. e simul. correspondem a experimental e simulação, respectivamente.

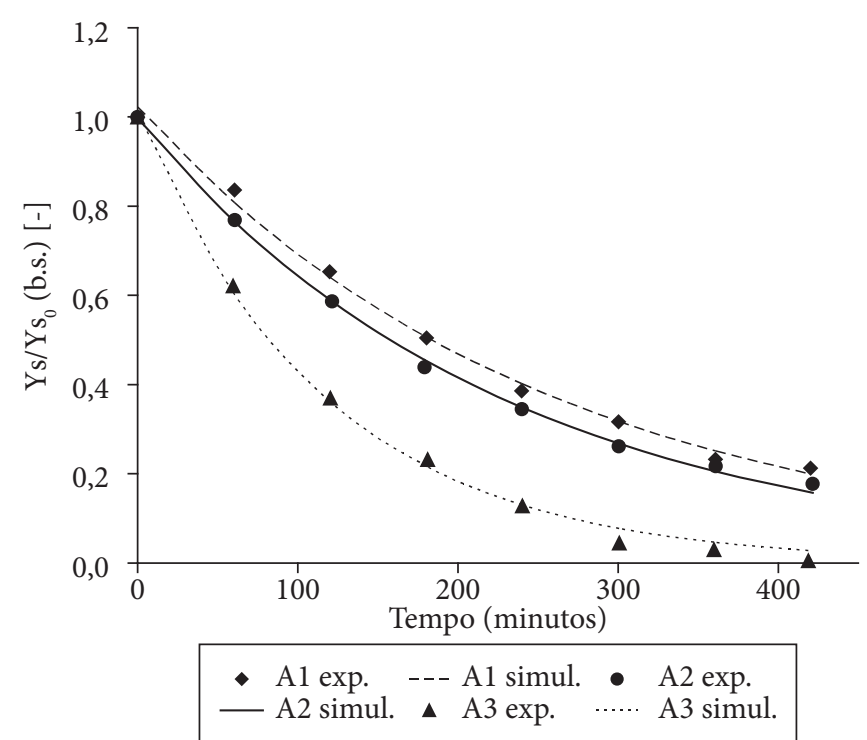

Figura 6. Cinética de secagem de abóbora, com diferentes temperaturas de ar de secagem com área de $12,5 \times 10^{-4} \mathrm{~m}^{2}$, desidratada por convecção forçada com ar à velocidade de $5,5 \times 10^{-4} \mathrm{~ms}^{-1}$; e as abreviações exp. e simul. correspondem a experimental e simulação, respectivamente.

Tabela 1. Grau de encolhimento em convecção natural.

\begin{tabular}{|c|c|c|c|c|c|c|c|c|c|c|c|c|}
\hline \multicolumn{13}{|c|}{ Grau de encolhimento em convecção natural } \\
\hline \multirow[t]{3}{*}{ Temperatura $\left({ }^{\circ} \mathrm{C}\right)$} & \multicolumn{12}{|c|}{ Encolhimento (\%) } \\
\hline & \multicolumn{3}{|c|}{$\left(\mathrm{E}_{0}-\mathrm{E}\right) / \mathrm{E}_{0}$} & \multicolumn{3}{|c|}{$\left(\mathrm{L}_{0}-\mathrm{L}\right) / \mathrm{L}_{0}$} & \multicolumn{3}{|c|}{$\left(\mathrm{C}_{0}-\mathrm{C}\right) / \mathrm{C}_{0}$} & \multicolumn{3}{|c|}{$\left(\mathrm{V}_{0}-\mathrm{V}\right) / \mathrm{V}_{0}$} \\
\hline & $\mathrm{A}_{1}$ & $\mathrm{~A}_{2}$ & $\mathrm{~A}_{3}$ & $\mathrm{~A}_{1}$ & $\mathrm{~A}_{2}$ & $\mathrm{~A}_{3}$ & $\mathrm{~A}_{1}$ & $\mathrm{~A}_{2}$ & $\mathrm{~A}_{3}$ & $\mathrm{~A}_{1}$ & $\mathrm{~A}_{2}$ & $\mathrm{~A}_{3}$ \\
\hline 50 & 41,3 & 46,1 & 48,6 & 30,6 & 27,1 & 37,1 & 32,0 & 24,9 & 21,2 & 72,3 & 50,8 & 64,3 \\
\hline 60 & 51,8 & 50,6 & 54,2 & 34,8 & 35,0 & 40,0 & 35,2 & 25,6 & 23,3 & 87,8 & 76,1 & 82,3 \\
\hline 70 & 55,1 & 51,9 & 58,1 & 34,5 & 33,4 & 43,3 & 33,4 & 25,1 & 24,5 & 86,0 & 71,4 & 82,1 \\
\hline
\end{tabular}

$\mathrm{E}=$ espessura; $\mathrm{L}=$ largura; $\mathrm{C}=$ comprimento; e subíndice $0=$ condição inicial. 
de secagem. A tendência a um aumento do grau de secagem foi observada com o aumento de velocidade do ar de 5,5 $\times 10^{-4} \mathrm{~ms}^{-1}$ e $1,65 \times 10^{-3} \mathrm{~ms}^{-1}$, porém de maneira bem menos expressiva que ao se passar de convecção natural para convecção forçada. A elevação da velocidade do ar promove uma maior difusão da umidade, resultando em elevadas taxas de secagem (McMINN; MAGEE, 1999; QUEIROZ; NEBRA, 2001; RAMESH et al., 2001; PANCHARIYA et al., 2002; KROKIDA et al., 2003; ANDRÉS; BILBAO; FITO, 2004). A abóbora contém um alto teor de umidade interna, o que faz com que a resistência interna seja a limitante no processo de transferência e que a velocidade do ar não seja tão significante quanto no caso de um produto contendo somente umidade superficial. A velocidade torna-se de menor influência no período final de secagem, no qual a resistência interna predomina e o coeficiente de difusão é menor. Resultados similares foram obtidos para secagem de alho (MANDABA; DRISCOLL; BUCLE, 1996), banana (LEITE, 2002) e batata, cenoura, pimenta, alho, cogumelo, cebola, cebolinha, vagem, milho, salsinha, moranga e tomate (KROKIDA et al., 2003).

A Tabela 2 mostra o efeito da temperatura e da velocidade sobre o grau de encolhimento de fatias de abóboras de diferentes áreas.

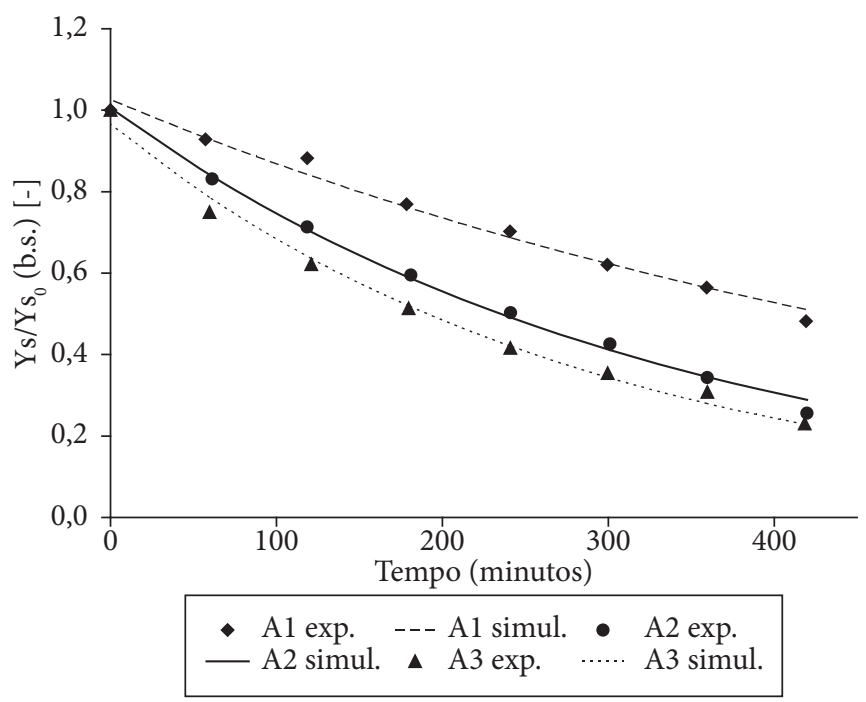

Figura 7. Cinética de secagem de abóbora, com diferentes velocidades do ar de secagem com área de $7,5 \times 10^{-4} \mathrm{~m}^{2}$, desidratada por convecção forçada com ar à temperatura de $50^{\circ} \mathrm{C}$, onde $\mathrm{V}_{1}$ e $\mathrm{V}_{2}$ correspondem à velocidade do ar de $5,5 \times 10^{-4} \mathrm{~ms}^{-1}$ e $1,65 \times 10^{-3} \mathrm{~ms}^{-1}$; C. Natural corresponde à convecção natural; e as abreviações exp. e simul. correspondem a experimental e simulação, respectivamente.
Observa-se que a influência da área e a da temperatura foram similares às observadas para convecção natural. A velocidade de ar afetou grandemente as dimensões das fatias de abóbora principalmente a $70^{\circ} \mathrm{C}$, aumentando o encolhimento em todas as dimensões. Novamente, para o formato $\mathrm{A}_{3}$, houve encolhimento mais pronunciado na largura e menor para o comprimento em relação às outras áreas, uma vez que este formato atingiu o maior grau de secagem em qualquer temperatura. Os resultados aqui obtidos também corroboram o trabalho de Mulet et al. (2000). Ao se comparar as Tabelas 1 e 2, verifica-se que o encolhimento volumétrico foi sempre menor em condições de convecção forçada. Ratti (1994), avaliando o encolhimento para batata, cenoura e maçã, verificou que o aumento da velocidade do ar resultou em produtos com menor encolhimento. Com base na Figura 5 e na Tabela 2, observa-se que a geometria $\mathrm{A}_{2}$ é a mais conveniente para a secagem de abóbora por convecção forçada, devido ao menor encolhimento volumétrico, considerando que os níveis de umidade final alcançados são próximos aos obtidos para a geometria $\mathrm{A}_{3}$. Para Ochoa et al. (2007), o encolhimento do volume e a área de cerejas desidratadas foram independentes da velocidade e temperatura do ar de secagem, mas dependentes da umidade final.

A Tabela 3 apresenta os coeficientes obtidos para a equação de ajuste das curvas de secagem (Equação 3), com dados de ajuste $\mathrm{r}^{2}$ e SE. Verifica-se que o coeficiente $\mathrm{k}_{0}$ esteve sempre próximo da unidade, o que condiz com o significado físico de umidade inicial e que de maneira geral, esta equação apresentou um bom ajuste aos dados experimentais.

\section{Conclusões}

A convecção forçada conduziu a um maior grau de secagem e menor grau de encolhimento que a convecção natural, porém o aumento de velocidade do ar não foi tão influente no teor final de umidade obtido em casos de convecção forçada. Visando uma secagem com menor encolhimento, recomendase o uso de fatias com volume de $6,25 \mathrm{~cm}^{3}\left(\mathrm{~A}_{2}\right)$ em secadores por convecção forçada a $50^{\circ} \mathrm{C}$ e à velocidade de $5,5 \times 10^{-4} \mathrm{~ms}^{-1}$. Esta velocidade, no secador utilizado, com área transversal de $0,97 \mathrm{~m}$ por $0,52 \mathrm{~m}$ equivale a uma vazão volumétrica de ar de $2,78 \times 10^{-4} \mathrm{~m}^{3} \mathrm{~s}^{-1}$.

Tabela 2. Grau de encolhimento em convecção forçada.

\begin{tabular}{|c|c|c|c|c|c|c|c|c|c|c|c|c|c|}
\hline \multicolumn{14}{|c|}{ Grau de encolhimento em convecção forçada } \\
\hline \multicolumn{2}{|c|}{ Condições } & \multicolumn{12}{|c|}{ Encolhimento (\%) } \\
\hline \multirow[t]{2}{*}{ Temperatura $\left({ }^{\circ} \mathrm{C}\right)$} & \multirow{2}{*}{$\begin{array}{c}\text { Veloc. } \times 10^{4} \\
{\left[\mathrm{~m}^{3} \mathrm{~s}^{-1}\right]}\end{array}$} & \multicolumn{3}{|c|}{$\left(\mathrm{E}_{0}-\mathrm{E}\right) / \mathrm{E}_{0}$} & \multicolumn{3}{|c|}{$\left(\mathrm{L}_{0}-\mathrm{L}\right) / \mathrm{L}_{0}$} & \multicolumn{3}{|c|}{$\left(\mathrm{C}_{0}-\mathrm{C}\right) / \mathrm{C}_{0}$} & \multicolumn{3}{|c|}{$\left(\mathrm{V}_{0}-\mathrm{V}\right) / \mathrm{V}_{0}$} \\
\hline & & $\mathrm{A}_{1}$ & $\mathrm{~A}_{2}$ & $\mathrm{~A}_{3}$ & $\mathrm{~A}_{1}$ & $\mathrm{~A}_{2}$ & $\mathrm{~A}_{3}$ & $\mathrm{~A}_{1}$ & $\mathrm{~A}_{2}$ & $\mathrm{~A}_{3}$ & $\mathrm{~A}_{1}$ & $\mathrm{~A}_{2}$ & $\mathrm{~A}_{3}$ \\
\hline 50 & 5,5 & 22,5 & 10,1 & 18,2 & 11,8 & 15,3 & 20,1 & 13,8 & 16,3 & 13,2 & 41,1 & 36,3 & 43,3 \\
\hline 50 & 16,5 & 35,2 & 41,1 & 47,6 & 30,6 & 20,1 & 21,2 & 23,0 & 24,9 & 21,2 & 65,4 & 64,7 & 67,5 \\
\hline 60 & 5,5 & 36,7 & 40,3 & 49,4 & 22,0 & 24,4 & 24,5 & 20,1 & 19,9 & 21,1 & 60,6 & 63,8 & 69,9 \\
\hline 70 & 16,5 & 67,0 & 67,7 & 73,0 & 37,2 & 35,4 & 43,3 & 36,6 & 35,1 & 35,5 & 86,9 & 86,5 & 90,1 \\
\hline
\end{tabular}


Tabela 3. Coeficientes de ajuste da Equação 3 aos dados experimentais de cinética de secagem de abóbora.

\begin{tabular}{|c|c|c|c|c|}
\hline Ensaio & $\mathrm{k}_{0}$ & $\mathrm{k}_{1} \times 10^{3}$ & $\mathrm{r}^{2}$ & SE \\
\hline \multicolumn{5}{|c|}{ Convecção natural } \\
\hline $\mathrm{A}_{1} \mathrm{~T}_{1}$ & 1,0261 & 1,662 & 0,9857 & 0,0206 \\
\hline $\mathrm{A}_{1} \mathrm{~T}_{2}$ & 1,0017 & 2,915 & 0,9406 & 0,0586 \\
\hline $\mathrm{A}_{1} \mathrm{~T}_{3}$ & 1,0666 & 6,363 & 0,9664 & 0,0640 \\
\hline $\mathrm{A}_{2} \mathrm{~T}_{1}$ & 1,0497 & 2,176 & 0,9786 & 0,0307 \\
\hline $\mathrm{A}_{2} \mathrm{~T}_{2}$ & 1,0350 & 3,082 & 0,9812 & 0,1097 \\
\hline $\mathrm{A}_{2} \mathrm{~T}_{3}$ & 1,0777 & 6,972 & 0,9608 & 0,0711 \\
\hline $\mathrm{A}_{3} \mathrm{~T}_{1}$ & 1,0319 & 2,193 & 0,9899 & 0,0207 \\
\hline $\mathrm{A}_{3} \mathrm{~T}_{2}$ & 1,0305 & 3,697 & 0,9902 & 0,0267 \\
\hline $\mathrm{A}_{3} \mathrm{~T}_{3}$ & 1,0369 & 8,082 & 0,9810 & 0,0477 \\
\hline \multicolumn{5}{|c|}{ Convecção forçada } \\
\hline $\mathrm{A}_{1} \mathrm{~T}_{1} \mathrm{~V}_{1}$ & 1,0051 & 2,971 & 0,9964 & 0,0142 \\
\hline$A_{1} T_{1} V_{2}$ & 0,9663 & 3,448 & 0,9920 & 0,0215 \\
\hline $\mathrm{A}_{1} \mathrm{~T}_{2} \mathrm{~V}_{1}$ & 0,9896 & 3,978 & 0,9969 & 0,0146 \\
\hline $\mathrm{A}_{1} \mathrm{~T}_{2} \mathrm{~V}_{2}$ & 1,0078 & 5,834 & 0,9978 & 0,0145 \\
\hline $\mathrm{A}_{1} \mathrm{~T}_{3} \mathrm{~V}_{1}$ & 0,9577 & 4,955 & 0,9804 & 0,0378 \\
\hline $\mathrm{A}_{1} \mathrm{~T}_{3} \mathrm{~V}_{2}$ & 1,0125 & 6,340 & 0,9952 & 0,0216 \\
\hline $\mathrm{A}_{2} \mathrm{~T}_{1} \mathrm{~V}_{1}$ & 1,0215 & 3,887 & 0,9961 & 0,0169 \\
\hline $\mathrm{A}_{2} \mathrm{~T}_{1} \mathrm{~V}_{2}$ & 1,0234 & 4,001 & 0,9941 & 0,0169 \\
\hline $\mathrm{A}_{2} \mathrm{~T}_{2} \mathrm{~V}_{1}$ & 0,9973 & 4,374 & 0,9985 & 0,0105 \\
\hline $\mathrm{A}_{2} \mathrm{~T}_{2} \mathrm{~V}_{2}$ & 0,9839 & 5,683 & 0,9977 & 0,0140 \\
\hline $\mathrm{A}_{2} \mathrm{~T}_{3} \mathrm{~V}_{1}$ & 1,0097 & 8,525 & 0,9970 & 0,0178 \\
\hline $\mathrm{A}_{2} \mathrm{~T}_{3} \mathrm{~V}_{2}$ & 1,0263 & 9,357 & 0,9873 & 0,0386 \\
\hline $\mathrm{A}_{3} \mathrm{~T}_{1} \mathrm{~V}_{1}$ & 1,0194 & 3,905 & 0,9955 & 0,0183 \\
\hline $\mathrm{A}_{3} \mathrm{~T}_{1} \mathrm{~V}_{2}$ & 1,0007 & 4,242 & 0,9975 & 0,0135 \\
\hline $\mathrm{A}_{3} \mathrm{~T}_{2} \mathrm{~V}_{1}$ & 0,9971 & 1,855 & 0,9927 & 0,0152 \\
\hline $\mathrm{A}_{3} \mathrm{~T}_{2} \mathrm{~V}_{2}$ & 1,0069 & 5,541 & 0,9977 & 0,0144 \\
\hline $\mathrm{A}_{3} \mathrm{~T}_{3} \mathrm{~V}^{1}$ & 1,0106 & 7,890 & 0,9934 & 0,0261 \\
\hline $\mathrm{A}_{3} \mathrm{~T}_{3} \mathrm{~V}_{2}$ & 1,0191 & 8,763 & 0,9898 & 0,0340 \\
\hline
\end{tabular}

Onde $\mathrm{k}_{0}$ e $\mathrm{k}_{1}$ correspondem a coeficientes de ajuste; $\mathrm{r}^{2}$ corresponde ao coeficiente de correlação; e SE ao erro padrão; $\mathrm{T}_{1}, \mathrm{~T}_{2}$ e $\mathrm{T}_{3}$ correspondem a 50,60 e $70^{\circ} \mathrm{C} ; \mathrm{e} \mathrm{V}_{1}$ e $\mathrm{V}_{2}$ a $5,5 \times 10^{-4} \mathrm{~ms}^{-1}$ e $1,65 \times 10^{-3} \mathrm{~ms}^{-1}$, respectivamente.

\section{Referências bibliográficas}

ALCINA, O. L. S.; SILVA, O. S.; BRASILEIRO, M. N. Drying kinetics of West Indian Cherry. In: Inter-American Drying Conference, 1997, Itu. Proceedings... Itu: IADC, 1997, p. 434-440.

ANDRÉS, A.; BILBAO, C.; FITO, P. Drying kinetics of apple cilynders under combined hot air-microwave dehydration. Journal of Food Engineering, v. 63, n. 1, p. 71-78, 2004.

AMBRÓSIO, C. L. B.; CAMPOS, F. A. C. S.; FARO, Z. Aceitabilidade de flocos desidratados de abóbora. Revista de Nutrição, v. 19, n. 1, p. 39-45, 2006.

AOAC - Association of Official Analytical Chemists. Official Methods of Analysis. 17 ed. Maryland, 2002.

ARÉVALO-PINEDO, A.; MURR, F. E. X. Influência da pressão, temperatura e pré-tratamentos na secagem a vácuo de cenoura $\mathrm{e}$ abóbora. Ciência e Tecnologia de Alimentos, v. 25, n. 4, p. 636-643, 2005.

ARIMA, H. K.; RODRIGUEZ-AMAYA, D. B. Carotenoid composition and vitamin A value of a squash and pumpkin from northeastern Brazil. Archivos Latinoamericanos de Nutrición, v. 40, n. 2, p. 284-92, 1990.
CANO-CHAUCA, M. et al. Drying curves and water evaluation of dryed banana. In: International Drying Symposium, 14, 2004, São Paulo. Proceedings... São Paulo: IDS, 2004, p. 2013-2020.

COELHO, A. D. et al. Avaliação da produção de fatias de abóbora desidratada utilizando uma combinação das técnicas de desidratação osmótica e secagem convectiva. In: Congresso Brasileiro de Sistemas Particulados, 30, 2002, São Carlos. Anais... São Carlos: UFSCAR, 2002. (CD - ROM).

HERNANDEZ, J. A.; PAVON, G.; GARCIA, M. A. Analytical solution of mass transfer equation considering shrinkage for modeling food-drying kinetics. Journal of Food Engineering, v. 45, n. 1, p. 1-10, 2000.

KARATHANOS, V. T. Determination of water content of dried fruits by drying kinetics. Journal of Food Engineering, v. 39, n. 4, p. 337-344, 1999.

KINGSLY, A. R. P. et al. Shrinkage for ber (Zizyphus Mauritian L.) fruits during sun drying. Journal of Food Engineering, v. 79, n. 1, p. 6-10, 2007.

KROKIDA, M. K. et al. Drying Kinetics of some vegetables. Journal of Food Engineering, v. 59, n. 4, p. 391-403, 2003.

LEITE, J. B. Uma contribuição ao estudo da secagem de banana em secadores de bandejas. Seropédica, 2002. 100 p. Dissertação (Mestrado em Ciência e Tecnologia de Alimentos), Departamento de Tecnologia de Alimentos, Universidade Federal Rural do Rio de Janeiro - UFRRJ.

LEITE, J. B.; MANCINI, M. C.; BORGES, S. V. Effect of drying temperature on the quality of dried bananas cv. Prata and d'água. Lebensmittel-Wissenschaft und Technologie, v. 40, n. 2, p. 319-323, 2007.

LEWICKI, P. P.; PAWLAK, G. Effect of drying on microstructure of plant tissue. Drying Technology, v. 21, n. 4, p. 657-683, 2003.

MADAMBA, P. S.; DRISCOLL, R. H.; BUCLE, K. A. The thin-layer drying characteristics of garlic slices. Journal of Food Engineering, v. 29, n. 1, p. 75-97, 1996.

MAYOR, L.; SERENO, A. M. Modelling shrinkage during convective drying of food materials: a review. Journal of Food Engineering, v. 61, n. 3, p. 373-386, 2004.

McMinN, W. A. M.; MAGEE, T. R. A. Principles, methods and applications of the convective drying of foodstuffs. Food Bioproducts and Processing, v. 77, n. 3, p. 175-193, 1999.

MOREIRA, R.; FIGUEIREDO, A.; SERENO, A. Shrinkage of apple disks during drying by warm air conveccion and freeze drying. Drying Technology, v. 18, n. 1-2, p. 279-294, 2000.

MULET, A. et al. Effect of shape on potato and cauliflower shinkage during drying. Journal of Food Engineering, v. 18, n. 6, p. 1201-1219, 2000

MURKOVIC, M.; MÜLLEDER, U.; NEUNTEU, H. Carotenoid content in different varieties of pumpkins. Journal of Food Composition and Analysis., v. 15, n. 6, p. 633-638, 2002.

NICOLETI, J. F; TELIS-ROMERO, R.; TELIS, V. R. N. Air-drying of fresh and osmotically pre-treated pinapple slices: fixed air temperature versus fixed slices temperature drying kinetcs. Drying Technology, v. 19, n. 9, p. 2175-2191, 2001.

OCHOA, M. R. et al. Analysis of shrinkage phenomenon of whole sweet cherry fruits (Prunus avium) during convective dehydration with very simple models. Journal of Food Engineering, v. 79, n. 2, p. 657-661, 2007.

PANCHARIYA, P. C.; POPOVIC, D.; SHARMA, A. L. Thin-layer modelling of black tea drying process. Journal of Food Engineering, v. 52 , n. 4 , p. $349-357,2002$. 
PARK, K. J.; YADO, M. K. M.; BROD, F. P. R. Estudo de secagem de pêra bartlett (Pyrus sp.) em fatias. Ciência e Tecnologia de Alimentos, v. 21, n. 3, p. 288-292, 2001.

PARK, K. J. Diffusion model with and without shrinkage during salted fish muscle drying. Drying Technology, v. 16, n. 3-5, p. 889-905, 1998.

PIMENTEL-GOMES, F. Curso de estatística experimental. São Paulo: Nobel, 1999.

PUIGALLI, J. R.; JOMAA, W.; JANNOT, Y. Shrinkage and density evolution during drying of tropical fruits: application to banana. Journal of Food Engineering, v. 64, n. 1, p. 103-109, 2004.
QUEIROZ, M. R.; NEBRA, S. A. Theoretical and experimental analysis of drying kinetics of bananas. Journal of Food Engineering, v. 47, n. 2, p. 127-132, 2001.

RAMESH, M. N. et al. Influence of processing parameters on the drying of spice paprika. Journal of Food Engineering, v. 49, n. 1, p. 63-72, 2001.

RATTI, C. Shrinkage during drying of foodstuffs. Journal of Food Engineering, v. 23, n. 1, p. 91-105, 1994. 